\title{
The adenoviral E1A oncoprotein activates the Smad7 promoter: Requirement of a functional E-box
}

\author{
VANDANA S. DOLE ${ }^{1,8}$, HANS SMOLA $^{2,9}$, STEVEN DOOLEY $^{3}$, HARUN M. SAID $^{4}$, \\ MONIKA OLDAK ${ }^{5,6}$, HERBERT J. PFISTER ${ }^{7}$ and SIGRUN SMOLA ${ }^{1,5}$ \\ ${ }^{1}$ Center for Molecular Medicine Cologne, University of Cologne; ${ }^{2}$ Department of Dermatology, University of Cologne, \\ Joseph-Stelzmann-Str. 9, D-50924 Cologne; ${ }^{3}$ Molecular Alcohol Research in Gastroenterology, II. Medical Clinic, \\ University Hospital Mannheim, Theodor-Kutzer-Ufer 1-3, D-68167 Mannheim; ${ }^{4}$ Department of Radiation Oncology, \\ University of Würzburg, Josef-Schneider-Str. 11, D-97080 Würzburg; ${ }^{5}$ Institute of Virology, Saarland University, \\ Kirrbergerstrasse, Building 47, D-66421 Homburg/Saar, Germany; ${ }^{6}$ Department of Histology and Embryology \\ Center of Biostructure Research, Medical University of Warsaw, Chalubinskiego 5, PL-02004 Warsaw, Poland; \\ ${ }^{7}$ Institute of Virology, University of Cologne, Fuerst-Pueckler-Str. 56, D-50935 Cologne, Germany
}

Received June 9, 2009; Accepted July 22, 2009

DOI: 10.3892/ijo_00000468

\begin{abstract}
DNA tumorviruses like adenoviruses (AdV) or human papillomaviruses (HPV) have adopted various strategies to interfere with antiproliferative transforming growth factor- $\beta$ (TGF-ß) signalling. Here we report that the AdV E1A oncoprotein is sufficient to induce Smad7 expression, an inhibitor of TGF- $ß$ signalling. E1A but not HPV oncoproteins activated the Smad7 promoter. A promoter proximal E-box was crucial for E1A-mediated transcriptional activity. E1A but not HPV oncoproteins induced specific binding activity at this E-box, which was identified as upstream stimulatory factor. In conclusion, these results unravel a novel mechanism of how the AdV E1A oncoprotein induces a cellular inhibitor of TGF- $ß$ signalling.
\end{abstract}

\section{Introduction}

In epithelial and hematopoietic cells transforming growth factor- $\beta$ (TGF- $\beta$ ) inhibits proliferation. TGF- $\beta$ signals through heteromeric complexes of type I and type II serine/threonine kinase receptors (TGF-ßR). Upon ligand binding, receptorregulated R-Smad proteins (i.e., Smad2 and 3) are recruited to the receptor complex and phosphorylated. Complexes formed between activated R-Smads and the common mediator

Correspondence to: Dr Sigrun Smola, Institute of Virology, Saarland University, Kirrbergerstrasse, Building 47, D-66421 Homburg/Saar, Germany

E-mail: sigrun.smola@uks.eu

Present addresses: ${ }^{8}$ Molecular Diagnostics Charles River, 251 Ballardvale St. Wilmington, MA 01887, USA; ${ }^{9}$ Paul Hartmann AG, P.O. Box 1420, D-89504 Heidenheim, Germany

Key words: adenovirus, human papillomavirus, oncoprotein, E1A, transforming growth factor, Smad
Co-Smad4 translocate to the nucleus, where they activate transcription in concert with interacting transcription factors and p300/CBP co-activators (reviewed in refs. 1,2).

Inhibitory Smads (Smad6 and 7) associate with type I receptors and interfere with recruitment and phosphorylation of R-Smads $(3,4)$, or lead to proteasomal degradation of the receptor complex (5). TGF-ß/Smad3 signalling itself induces Smad7 expression, which mediates an inhibitory feedback loop (4,6-8). Smad7 is also up-regulated by various other stimuli (9-12).

The TGF- $\beta$ response element of the $\operatorname{Smad} 7$ promoter is located in a region highly conserved among different species. It consists of a functional Smad binding element (SBE), a 3-bp adjacent E-box sequence (CACGTG) and an overlapping activator protein-1 (AP-1) site $(6,13)$. E-boxes are recognised by members of the basic-helix-loop-helix leucinezipper transcription factor family. These include Myc proteins, microphthalmia-associated transcription factor and the highly related factors TFEB, TFEC and TFE3, as well as the upstream regulatory factors USF-1 and -2 (14). In hepatocarcinoma HepG2 cells, USF is present in constitutive and TGF-ßinducible protein complexes binding to the Smad7 promoter (6). Also, TFE3 can bind to the E-box of the Smad7 promoter. It synergises with $\mathrm{Smad} 3$ in TGF- $\beta$-mediated transcriptional activation of the Smad7 gene (15).

Proliferating host cells are prerequisites for the life cycles of DNA-tumor viruses such as adenoviruses (AdV) and human papillomaviruses (HPV). They have acquired strategies to counteract TGF- $\beta$ signalling, which release epithelial cells from TGF- $\beta$-mediated growth inhibition. In this regard, AdV E1A is the best studied oncoprotein, which interferes with TGF- $\beta$ signalling at various levels. It down-regulates TGFßRII, interacts with R-Smads and competes for the important transcriptional co-activator p300 (16-20). Similarly, E7 oncoproteins from various HPV as well as HPV5E6 directly interact with Smad proteins and inhibit their activity (21-23).

Here, we describe a novel strategy of the AdV E1A oncoprotein, which affects a TGF- $\beta$ antagonising pathway. Our 
data show for the first time that E1A but not HPV oncoproteins induce Smad7 expression, a cellular inhibitor of TGF- $\beta$ signalling.

\section{Materials and methods}

Cell lines. The cervical carcinoma cell lines SiHa (ATCC HTB-35), CaSki (ATCC CRL-1550) (both HPV 16-positive), C33A (ATCC HTB-31, HPV and AdV-negative), as well as the AdV-transformed cell line 293 (ATCC CRL-1573) and its derivative 293T (24) were cultured in DMEM (Invitrogen, Carlsbad, CA). All media were supplemented with $100 \mathrm{U} / \mathrm{ml}$ penicillin, $0.1 \mathrm{mg} / \mathrm{ml}$ streptomycin, $1 \mathrm{mM}$ sodium pyruvate, $2 \mathrm{mM}$ L-alanyl-L-glutamin, and 10 or $0.5 \%$ heat inactivated fetal calf serum (FCS) as indicated (all from Invitrogen).

Plasmids and plasmid construction. The pcDNA-16E6 expression vector was obtained by introducing a 630-bp fragment encoding HPV16E6 into EcoRV sites of pcDNA3.1 ${ }^{+}$ (Invitrogen). The pcDNA-16E7 plasmid was constructed as previously described (25). AdV2 E1A in pXJ41 (pXJ41-E1A) and respective empty vector were kindly provided by Dr Gertrud Steger. For stable transfection the E1A coding sequence was re-cloned from pXJ41-E1A into pDNA3.1+. Briefly, E1A was released from pXJ41 with EcoRI and $B g l \mathrm{II}$, cloned into EcoRI and BamHI sites of pBS II SK ${ }^{+}$ (Stratagene, La Jolla, CA), cut with EcoRI and NotI and subcloned into pcDNA3. $1^{+}$. pCMV-EGFP encoding the enhanced green fluorescent protein gene under the control of the human CMV-immediate early-promoter was kindly provided by Dr W. Krauss.

The rat Smad7 promoter $\mathrm{p}(-1280)-\mathrm{Smad} 7$ prom-Luc construct (S7-Luc), the deletion constructs p(-625)Smad7prom-Luc (S7-625) and p(-469)-Smad7prom-Luc (S7-469), as well as p(-1280)-Smad7prom-Luc constructs with disrupted SBE (S7-SBE*) or E-box elements (S7-Ebox*, replacing the CACGTG by GAATTC or S7-Ebox-del with deleted Ebox) have previously been described (6).

Transient transfection and luciferase assay. C33A cells were seeded at a density of $1.2 \times 10^{5}$ cells/well in 12 -well culture plates (Renner, Dannstadt, Germany). After $24 \mathrm{~h}$ the medium was changed to $0.5 \mathrm{ml}$ containing $0.5 \%$ FCS. Next, cells were transfected using FuGENE 6 transfection reagent according to the manufacturer's instructions (Roche Diagnostics $\mathrm{GmbH}$, Mannheim, Germany) with $0.2 \mu \mathrm{g}$ of the respective luciferase reporter construct and 30 or $120 \mathrm{ng}$ of $\mathrm{pXJ} 41-\mathrm{E} 1 \mathrm{~A}$ or the same amounts of pcDNA-16E6 or pcDNA-16E7 expression plasmids (25). pCMV-EGFP $(0.1 \mu \mathrm{g})$ was used to control transfection efficiency. Total amount of DNA was adjusted to $0.8 \mu \mathrm{g}$ with respective empty expression vector. Twentyfour hours after transfection medium was changed again. Twenty-four hours later cells were detached and transfection efficiencies were determined by flow cytometry of EGFP (FACSCalibur, Becton-Dickinson, Heidelberg, Germany). Cellular lysates were prepared as described previously (26) and assayed for luciferase activity using a model LB9501 luminometer (Berthold, Wildbad, Germany). The values were normalised to the percentages of EGFP-positive cells and protein contents of the lysates.
Electrophoretic mobility shift assays (EMSA). Nuclear extracts were prepared from C33A cells transiently transfected with pXJ41-E1A, pXJ41, pcDNA-16E6, pcDNA-16E7 or pcDNA3. $1^{+}$vector. Six hours post transfection cells were processed as described previously (6). Double stranded oligonucleotides from the rat Smad7 promoter designated S7wt (964-998, according to GenBank accession no. AF156727) comprising the SBE, AP-1 and E-box elements and mutated versions thereof $\left(\mathrm{SBE}^{*}, \mathrm{E}-\mathrm{box}{ }^{*}\right.$ and $\left.\mathrm{AP}^{*}\right)$ (6) were end-labeled with $\left[\gamma^{32} \mathrm{P}\right]-\mathrm{ATP}$ using polynucleotide kinase. Binding reactions were performed for $20 \mathrm{~min}$ at room temperature in a $20 \mu \mathrm{l}$ volume containing $10 \mu \mathrm{g}$ of nuclear extracts, $200 \mathrm{pg}$ of labeled oligonucleotides, 0.1 M Tris- $\mathrm{HCl}, \mathrm{pH} 7.5,0.5 \mathrm{M} \mathrm{NaCl}$, $0.05 \mathrm{M}$ EDTA, $15 \%$ glycerine, $25 \mathrm{ng} / \mathrm{ml}$ poly $(\mathrm{dIdC}), 1 \mathrm{mg} / \mathrm{ml}$ bovine serum albumin, $25 \mu \mathrm{g} / \mathrm{ml}$ aprotinin, $0.05 \mathrm{mg} / \mathrm{ml} \mathrm{ssDNA}$, $12 \mathrm{mM}$ dithiothreitol, $1.5 \mathrm{mM}$ phenylmethylsulphonylfluoride (Sigma-Aldrich, St. Louis, MO). In competition experiments unlabeled oligonucleotides were added at 50-fold excess. In supershift experiments $0.5 \mu \mathrm{g}$ of monoclonal anti-TFE3 (kindly provided by Dr B. Lüscher) or MOPC-21 antibodies (Sigma-Aldrich) or $2 \mu \mathrm{g}$ of the polyclonal antibodies antiUSF1, anti-Smad2, anti-Smad3, anti-Smad4 (sc-8983, sc-6200, sc-6202, sc-7154; all from Santa Cruz Biotechnology Inc., Santa Cruz, CA) or rabbit immunoglobulin (rabbit Ig, SigmaAldrich) were pre-incubated with nuclear extracts for $40 \mathrm{~min}$ on ice. Protein-DNA complexes were resolved in $5 \%$ polyacrylamide gels containing $0.5 \mathrm{x}$ TBE.

RNA preparation and RT-PCR. C33A cells $\left(1 \times 10^{6}\right)$ were seeded in $10 \mathrm{~cm}$ plates. After $24 \mathrm{~h}$ they were transfected with $10 \mu \mathrm{g}$ of linearised pcDNA3. $1^{+}$or pcDNA-E1A expression plasmid and selected in $1000 \mu \mathrm{g} / \mathrm{ml} \mathrm{G} 418$ for 3 weeks. Total RNA was isolated from these cells as well as from $\mathrm{SiHa}$, CaSki, 293 and 293T cells (Qiagen, Hilden, Germany). First strand synthesis was performed using oligo-dT primers and the Omniscript RT kit (Qiagen). A commercial primer set was used for B-actin cDNA specific RT-PCR according to the manufacturer's instructions (Stratagene). E1A was amplified with the 5'-ttggaccagctgatcgaag-3' and 5'-ctgccgggaaaggtg agg-3' primers. Smad7 specific RT-PCR was performed in $50 \mu 1$ according to Koinuma et al (27) applying the following PCR conditions: 25 cycles with denaturation at $94^{\circ} \mathrm{C}$ for $45 \mathrm{sec}$, annealing at $60^{\circ} \mathrm{C}$ for $45 \mathrm{sec}$ and extension at $72^{\circ} \mathrm{C}$ for $45 \mathrm{sec}$.

RT-PCR products from the different cell types were separated on the same $2.5 \%$ agarose gel and photographs were taken. RT-PCR product intensities of the virally transformed cells were compared with those of C33A cells, which had been analysed on the same gel.

\section{Results}

Smad7 is constitutively expressed in HPV-and AdV-transformed cell lines. The cervical carcinoma cell lines SiHa, CaSki (both HPV16-positive) and C33A (HPV-negative and AdV-negative), as well as the adenovirus-transformed cell line 293, and its derivative $293 \mathrm{~T}$ additionally expressing the large T antigen of polyomavirus SV40, were investigated for Smad7 expression by RT-PCR. Strong signals were obtained for all virally transformed cell lines (Fig. 1A), whereas HPV and AdV-negative C33A cells displayed much lower Smad7 
A

\section{B}

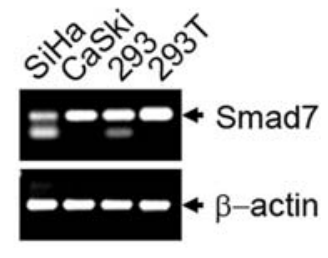

C

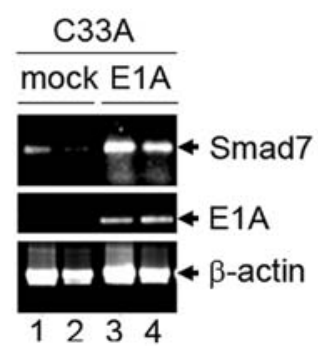

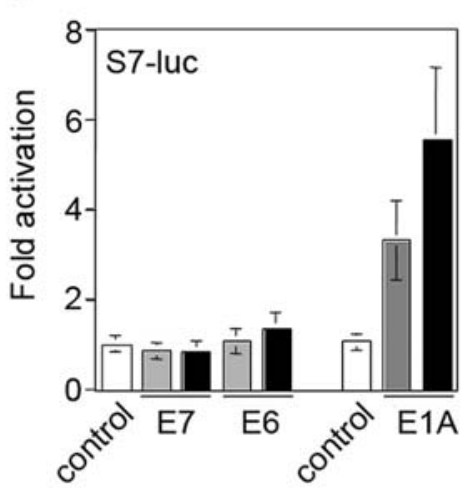

Figure 1. Smad7 expression in AdV- or HPV-transformed cells. (A) Total RNA was prepared from SiHa, CaSki, 293 and 293T cells. RT-PCR was performed for Smad7 (upper panel) and B-actin as control (lower panel). Ten $\mu \mathrm{l}$ of each reaction were separated on a $2.5 \%$ agarose gel (same gel as C33A cells shown in (C)). (B) Effects of HPV oncoproteins and AdV E1A on transactivation of the Smad7 promoter. C33A cells were transfected with $0.2 \mu \mathrm{g}$ of the wild-type rat Smad7-luciferase reporter construct S7-Luc, $0.1 \mu \mathrm{g}$ pCMV-EGFP and empty vector control (white column), $30 \mathrm{ng}$ (grey column), or $120 \mathrm{ng}$ (black column) of pDNA3.1+ $1^{+}$plasmids encoding HPV16E7, HPV16E6 or pXJ41 encoding AdV2 E1A. The total amount of DNA was adjusted with respective empty expression vector. Normalised luciferase activities of the control (empty expression vector only) were set to one. At least three independent experiments were conducted in triplicates and averaged. (C) Expression of Smad7 in C33A cells stably transfected with E1A. C33A cells were transfected with E1A in pcDNA3.1+ (right panel) or empty expression vector (mock, left panel) and investigated by RT-PCR for Smad7 (upper panel), E1A (middle panel) or ß-actin mRNA expression (lower panel). Lanes 1 and 3 show $20 \mu \mathrm{l}$, lanes 2 and $410 \mu \mathrm{l}$ of a representative RT-PCR reaction. To compare results from C33A cells with virally transformed cells, all RT-PCR products were separated on the same gel as in (A).

RT-PCR signals. This is shown in Fig. 1C lane 2, where identical amounts of cDNA were analysed on the same gel.

E1A activates the Smad7 promoter. Since all virally transformed cell lines expressed Smad7, we were interested, whether individual oncoproteins were able to directly activate the Smad7 promoter. C33A cells were transiently transfected with a reporter construct under the control of the Smad7 promoter. Co-transfection of expression vectors encoding HPV16E6 and E7 oncogenes did not alter Smad7 promoter activity. Functionality of the HPV constructs was verified in independent assays, where regulation of other cellular genes was tested [(22) and unpublished data]. In contrast, $120 \mathrm{ng}$ of E1A expression plasmid led to an almost 6-fold induction of Smad7 promoter activity (Fig. 1B).

In order to investigate whether E1A was able to activate the endogenous Smad7 gene, C33A cells were stably transfected with pcDNA-E1A expression plasmid or empty vector as a control. As shown in Fig. 1C (lanes 3 and 4), endogenous Smad7 mRNA levels were up-regulated by E1A in C33A cells. These data demonstrated for the first time that E1A can activate the Smad7 promoter and induce Smad7 expression.

\section{Mutation within the E-box abolishes E1A-mediated activation} of the Smad7 promoter. To narrow down the E1A responsive promoter region, deletion constructs and mutated versions of the Smad7 promoter were investigated in C33A cells transfected with or without E1A expression plasmid. Basal activities of deleted constructs, starting from position -625 (S7-625) or position -469 (S7-469), as well as mutated constructs, in which SBE or E-box elements had been inactivated by point-mutations (S7-SBE*, S7-Ebox*) (6), were slightly elevated by $2-2.5$-fold in comparison to the wild-type construct (starting from position -1280) (Fig. 2A). Only a construct containing sequences from positions -1280
A

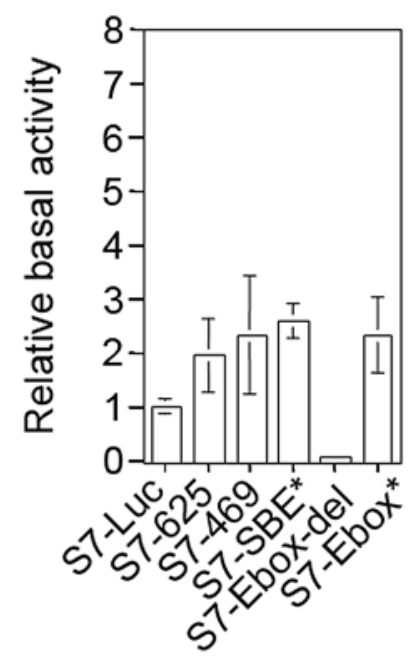

B

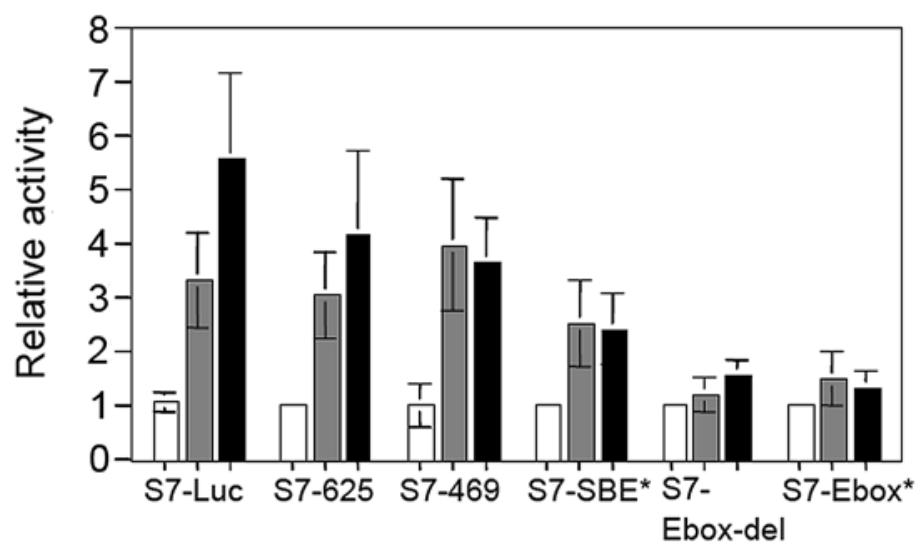

Figure 2. Basal (A) and E1A-inducible (B) activities of deletion constructs and mutated versions of the Smad7 promoter. The S7-Luc wild-type reporter construct (same as in Fig. 1B), S7-625, S7-469, S7-SBE*, S7-Ebox-del or S7-Ebox* and pCMV-EGFP vector were transfected into C33A cells without (white column) or with $30 \mathrm{ng}$ (grey column) or $120 \mathrm{ng}$ (black column) of E1A-pXJ41 expression plasmid. The total amount of DNA was adjusted with empty expression vector pXJ41. Relative luciferase activities were determined as in Fig. 1B. In (A), the activity of S7-Luc was set to 1. In (B), the basal activity of each reporter construct (with empty expression vector $\mathrm{pXJ} 41$ only) was set to one. 
A

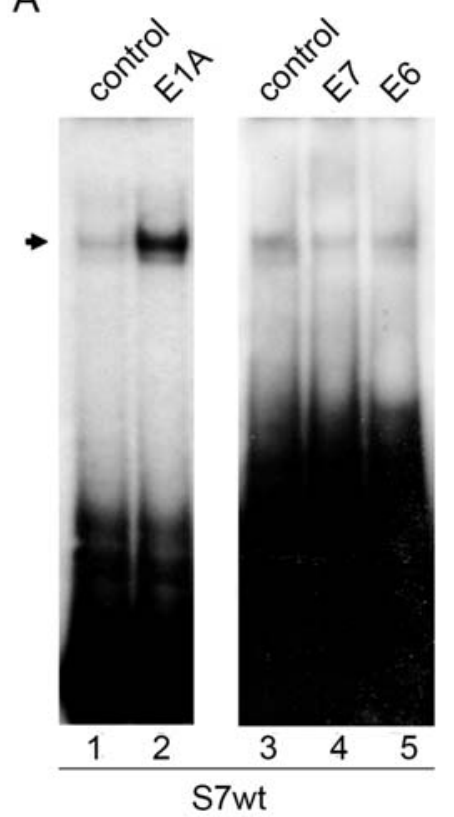

B

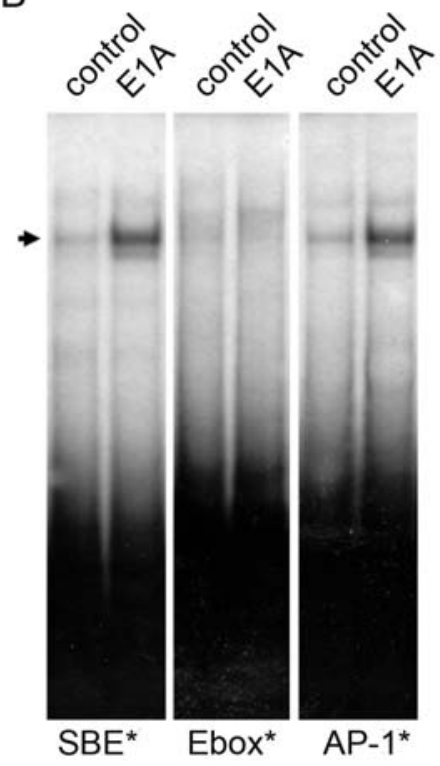

C

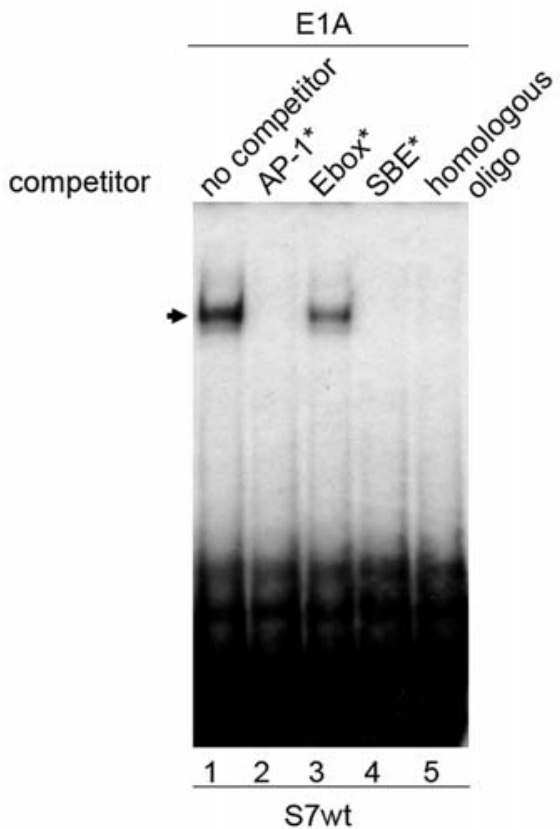

D

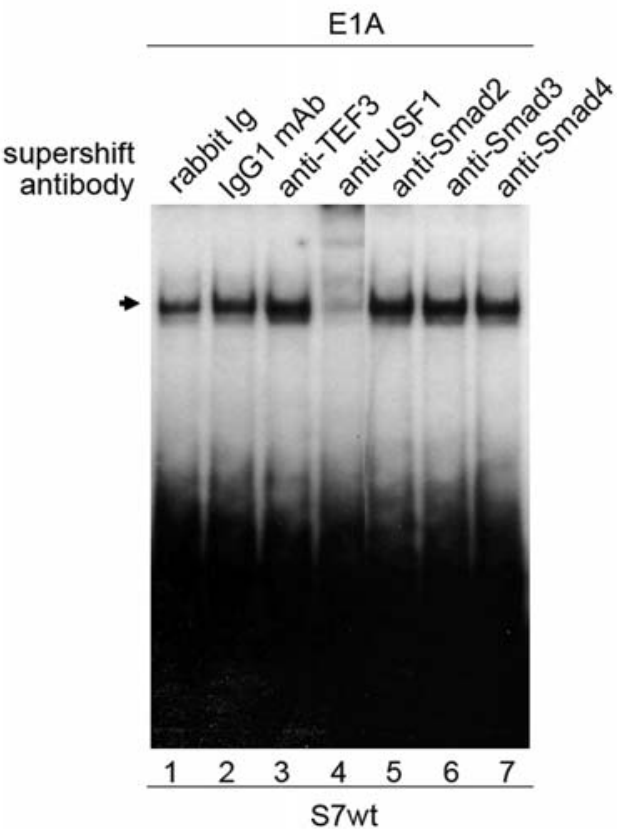

Figure 3. Characterisation of the E1A-inducible binding activity at the S7wt oligonucleotide comprising SBE, Ebox and AP-1 binding sites. (A) Nuclear extracts from C33A cells transiently transfected with pXJ41 (lane 1), E1A in pXJ41 (lane 2), pcDNA3.1 ${ }^{+}$(lane 3), 16E7 (lane 4) and 16E6 in pcDNA3.1 (lane 5) were prepared and analysed by EMSA using the $\left[{ }^{32} \mathrm{P}\right]$-labelled S7wt oligonucleotide. The arrow indicates the most prominent binding activity present in nuclear extracts of E1A transfected cells. (B) Nuclear extracts from C33A cells transiently transfected with E1A in pXJ41 or vector alone were analysed by EMSA using $\left[{ }^{32} \mathrm{P}\right]$-labelled S7 oligonucleotides comprising mutated SBE (SBE*), mutated Ebox (Ebox $\left.{ }^{*}\right)$ or mutated AP-1 (AP-1 ${ }^{*}$ ) sites, respectively. (C) Competition of E1A-inducible binding activity at the S7wt oligonucleotide (lane 1) with 50-fold excess of AP-1* (lane 2), Ebox* (lane 3), SBE* (lane 4) or homologous S7wt oligonucleotides (lane 5). (D) Identification of the E1A-inducible binding activity by supershift analysis. Nuclear extracts from C33A cells transiently expressing E1A were pre-incubated for $40 \mathrm{~min}$ on ice with $2 \mu \mathrm{g}$ of non-specific rabbit Ig (lane 1), $0.5 \mu \mathrm{g}$ MOPC-21 (lane 2 , isotype control for anti-TFE3) as controls, $0.5 \mu \mathrm{g}$ anti-TFE3 (lane 3), $2 \mu \mathrm{g}$ of the polyclonal rabbit anti-USF-1 (lane 4) or anti-Smad2-4 (lanes 5-7). Binding to the S7wt oligonucleotide was determined by EMSA. The arrow indicates the major binding activity induced in E1A transfectants.

to -335 with deletion of the E-box and its 3'-flanking promoter sequences (S7-Ebox-del) had lost basal activity in C33A cells, in a similar way as previously reported for HepG2 cells (6).

In order to assess inducibility by E1A and to facilitate comparison of the different constructs, their basal activities were set to 1 each (Fig. 2B). Ectopic E1A expression still induced activation of the -625 and -469 deletion constructs up to 4-fold. Activation of the construct with an SBE element mutation was reduced to 2.5 -fold. Responsiveness to E1A was almost completely lost in E-box deficient and E-box mutated constructs (Fig. 2B) indicating that E1A-mediated activation critically depends on an intact E-box. 
E1A induces USF-1 binding activity at the Smad7 promoter. To determine the E1A-dependent mechanism of Smad7 gene regulation, nuclear extracts from $\mathrm{C} 33 \mathrm{~A}$ cells transfected with E1A, HPV16E6 and E7 expression plasmids or empty vectors were investigated by EMSA. Wild-type Smad7 oligonucleotides (S7wt) comprised the proximal SBE, AP-1 and E-box elements of the Smad7 promoter (-356 to -322). Strong induction of binding activities was observed in extracts from E1A transfected cells but not from E6 or E7 transfectants (Fig. 3A). One prominent band was observed, which was accompanied by a less intense slightly faster migrating band. Since E1A does not bind to DNA itself, these data suggested that E1A led to induction or to activation of a cellular factor binding to the Smad7 promoter.

To characterise binding activities further, EMSAs were performed with $\mathrm{S} 7$ promoter oligonucleotides mutated in either the SBE, AP-1 binding site or the E-box. Oligonucleotides comprising mutated SBE or AP-1 elements still displayed strong E1A-mediated binding activity. However, no DNA binding activity was detected, when the E-box was mutated (Fig. 3B). In competition experiments binding activities were completely abolished when unlabeled homologous S7wt oligonucleotides or S7 oligonucleotides with mutated AP-1 or SBE sites were employed. In contrast, binding activity was preserved when an S7 oligonucleotide comprising a mutated E-box element was used as competitor (Fig. 3C). This confirmed the results obtained in Fig. 3B.

In order to define the nature of the E1A-inducible protein complex binding to the Smad7 promoter, supershift analyses were performed. As shown in Fig. 3D, E1A-mediated binding activity at the S7wt oligonucleotide was neither supershifted by antibodies directed against Smads2-4, nor by antiTFE3 or control antibodies. Only antibodies directed against the E-box binding protein USF-1 led to a complete supershift.

\section{Discussion}

In this study we show that both HPV-and AdV-transformed cells may constitutively express Smad7. The AdV E1A oncoprotein activated endogenous $\mathrm{Smad} 7$ transcription. Activation of the Smad7 promoter by E1A was dependent on a functional E-box, where E1A induced binding activity of the transcription factor USF-1. This was in contrast to HPV16 encoded oncoproteins, which neither directly activated the Smad7 promoter, nor induced USF-1 binding activity.

USF proteins are key components of the transcription machinery. They are important factors in gene regulation networks, including stress and immune responses, cell cycle and proliferation. USF factors are ubiquitously expressed with different cell-specific ratios of USF homo- and heterodimers (28). In transformed cells, mostly antiproliferative USF properties were studied (29). Their transcriptional activity is promoter and context specific, depending on factors expressed in the respective cell type (30). USF factors can mediate TGF- $B$ responses depending on an E-box within the regulatory region of activated genes, as previously shown for the plasminogen activator inhibitor-1 (31).

Constitutive or TGF- $\beta$-inducible USF binding activity has also been demonstrated for the Smad7 promoter (6). Both,
USF and Smad3 mediate a negative feedback response to TGF- $\beta$ stimulation, thereby limiting the antiproliferative activity of this cytokine. E1A has adopted a similar strategy to induce expression of the TGF- $\beta$ inhibitor Smad7. We show that it employs an E-box-dependent mechanism and the most prominent binding activity induced by E1A at the Smad7 promoter has been identified as USF-1. Thus, E1A like TGF- $\beta$ uses a primarily anti-proliferative transcription factor for Smad7 gene activation.

Additional analysis revealed that E1A did not increase USF-1 protein expression levels (data not shown). Interestingly, it was previously reported that E1A may associate with USF (previously termed as major late transcription factor) (32) and enhance gene transcription from USF binding sites (33). Several studies have demonstrated that multiple signal transduction pathways including the p38 stress activated kinase pathway (34), the protein kinase A and $\mathrm{C}$ pathways (35), the cdk1 pathway (36) and the PI3-kinase pathway (37) can modulate USF DNA-binding activity. The molecular mechanism, how the E1A oncoprotein leads to induction of USF binding activity at the $\mathrm{Smad} 7$ promoter, is currently unclear and will be subject of future studies.

Smad7 up-regulation may represent a novel strategy, how virally transformed cells counteract anti-proliferative TGF-ßmediated signalling. In this study we observed constitutive Smad7 expression in both AdV and HPV transformed cell lines. HPV oncoproteins share a variety of functions with AdV E1A (38-40), including binding and inhibition of R-Smads (21-23). The mechanism identified here appears to be unique for E1A and was not directly attributable to HPV oncoproteins. Thus, it can be speculated that other cellular factors contribute to increased Smad7 expression in HPV-positive tumor cells.

Together, our results describe a novel mechanism of how E1A induces a cellular inhibitor of TGF- $\beta$ signalling, a function apparently not shared by HPV oncoproteins.

\section{Acknowledgements}

This work was supported by a grant from the Köln Fortune program and the Deutsche Forschungsgemeinschaft through the SFB 670 to S. Smola. AdV2 E1A in pXJ41 (pXJ41-E1A) and respective empty vector were kindly provided by Dr Gertrud Steger. Dr B. Lüscher is thanked for providing antiTFE3 antibody used in this study. We are grateful to Corinna Pick, Ute Sandaradura de Silva and Alexandra van Mil for excellent technical assistance.

\section{References}

1. Feng XH and Derynck R: Specificity and versatility in TGFsignaling through Smads. Annu Rev Cell Dev Biol 21: 659-693, 2005.

2. Massague J: TGFbeta in cancer. Cell 134: 215-230, 2008.

3. Hayashi H, Abdollah S, Qiu Y, Cai J, Xu YY, Grinnell BW, Richardson MA, Topper JN, Gimbrone MA Jr, Wrana JL and Falb D: The MAD-related protein Smad7 associates with the TGFbeta receptor and functions as an antagonist of TGFbeta signaling. Cell 89: 1165-1173, 1997.

4. Nakao A, Afrakhte M, Moren A, Nakayama T, Christian JL, Heuchel R, Itoh S, Kawabata M, Heldin NE, Heldin CH and ten Dijke P: Identification of Smad7, a TGFbeta-inducible antagonist of TGF-beta signalling. Nature 389: 631-635, 1997. 
5. Kavsak P, Rasmussen RK, Causing CG, Bonni S, Zhu H, Thomsen GH and Wrana JL: Smad7 binds to Smurf2 to form an E3 ubiquitin ligase that targets the TGF beta receptor for degradation. Mol Cell 6: 1365-1375, 2000.

6. Stopa M, Anhuf D, Terstegen L, Gatsios P, Gressner AM and Dooley S: Participation of Smad2, Smad3, and Smad4 in transforming growth factor beta (TGF-beta)-induced activation of Smad7. THE TGF-beta response element of the promoter requires functional Smad binding element and E-box sequences for transcriptional regulation. J Biol Chem 275: 29308-29317, 2000.

7. Von Gersdorff G, Susztak K, Rezvani F, Bitzer M, Liang D and Bottinger EP: Smad3 and Smad4 mediate transcriptional activation of the human Smad7 promoter by transforming growth factor beta. J Biol Chem 275: 11320-11326, 2000.

8. Nagarajan RP, Zhang J, Li W and Chen Y: Regulation of Smad7 promoter by direct association with Smad3 and Smad4. J Biol Chem 274: 33412-33418, 1999.

9. Ulloa L, Doody J and Massague J: Inhibition of transforming growth factor-beta/SMAD signalling by the interferon-gamma/ STAT pathway. Nature 397: 710-713, 1999.

10. Bitzer M, von Gersdorff G, Liang D, Dominguez-Rosales A Beg AA, Rojkind $\mathrm{M}$ and Bottinger EP: A mechanism of suppression of TGF-beta/SMAD signaling by NF-kappa B/RelA. Genes Dev 14: 187-197, 2000.

11. Quan T, He T, Voorhees JJ and Fisher GJ: Ultraviolet irradiation induces Smad7 via induction of transcription factor AP-1 in human skin fibroblasts. J Biol Chem 280: 8079-8085, 2005.

12. Dooley S, Said HM, Gressner AM, Floege J, En-Nia A and Mertens PR: Y-box protein-1 is the crucial mediator of antifibrotic interferon-gamma effects. J Biol Chem 281: 1784-1795, 2006.

13. Brodin G, Ahgren A, ten Dijke P, Heldin CH and Heuchel R: Efficient TGF-beta induction of the $\mathrm{Smad} 7$ gene requires cooperation between AP-1, Sp1, and Smad proteins on the mouse Smad7 promoter. J Biol Chem 275: 29023-29030, 2000.

14. Corre S and Galibert MD: Upstream stimulating factors: highly versatile stress-responsive transcription factors. Pigment Cell Res 18: 337-348, 2005.

15. Hua X, Miller ZA, Benchabane H, Wrana JL and Lodish HF: Synergism between transcription factors TFE3 and Smad3 in transforming growth factor-beta-induced transcription of the Smad7 gene. J Biol Chem 275: 33205-33208, 2000.

16. Tarakanova VL and Wold WS: Transforming growth factor beta1 receptor II is downregulated by E1A in adenovirus-infected cells. J Virol 77: 9324-9336, 2003.

17. Datto MB, Hu PP, Kowalik TF, Yingling J and Wang XF: The viral oncoprotein E1A blocks transforming growth factor betamediated induction of p21/WAF1/Cip1 and p15/INK4B. Mol Cell Biol 17: 2030-2037, 1997.

18. Shen X, Hu PP, Liberati NT, Datto MB, Frederick JP and Wang XF: TGF-beta-induced phosphorylation of Smad3 regulates its interaction with coactivator p300/CREB-binding protein. Mol Biol Cell 9: 3309-3319, 1998.

19. Nishihara A, Hanai JI, Okamoto N, Yanagisawa J, Kato S, Miyazono K and Kawabata M: Role of p300, a transcriptional coactivator, in signalling of TGF-beta. Genes Cells 3: 613-623, 1998.

20. Nishihara A, Hanai J, Imamura T, Miyazono K and Kawabata M: E1A inhibits transforming growth factor-beta signaling through binding to Smad proteins. J Biol Chem 274: 28716-28723 1999.

21. Lee DK, Kim BC, Kim IY, Cho EA, Satterwhite DJ and Kim SJ: The human papilloma virus E7 oncoprotein inhibits transforming growth factor-beta signaling by blocking binding of the Smad complex to its target sequence. J Biol Chem 277: 38557-38564, 2002 .

22. Habig M, Smola H, Dole VS, Derynck R, Pfister H and Smola-Hess S: E7 proteins from high- and low-risk human papillomaviruses bind to TGF-beta-regulated Smad proteins and inhibit their transcriptional activity. Arch Virol 151: 1961-1972, 2006.
23. Mendoza JA, Jacob Y, Cassonnet P and Favre M: Human papillomavirus type 5 E6 oncoprotein represses the transforming growth factor beta signaling pathway by binding to SMAD3. J Virol 80: 12420-12424, 2006.

24. Pear WS, Nolan GP, Scott ML and Baltimore D: Production of high-titer helper-free retroviruses by transient transfection. Proc Natl Acad Sci USA 90: 8392-8396, 1993.

25. Smola-Hess S, Pahne J, Mauch C, Zigrino P, Smola H and Pfister HJ: Expression of membrane type 1 matrix metalloproteinase in papillomavirus-positive cells: role of the human papillomavirus (HPV) 16 and HPV8 E7 gene products. J Gen Virol 86: 1291-1296, 2005.

26. Hadaschik D, Hinterkeuser K, Oldak M, Pfister HJ and SmolaHess S: The papillomavirus E2 protein binds to and synergizes with C/EBP factors involved in keratinocyte differentiation. J Virol 77: 5253-5265, 2003.

27. Koinuma D, Shinozaki M, Komuro A, Goto K, Saitoh M, Hanyu A, Ebina M, Nukiwa T, Miyazawa K, Imamura T and Miyazono K: Arkadia amplifies TGF-beta superfamily signalling through degradation of Smad7. EMBO J 22: 6458-6470, 2003.

28. Sirito M, Lin Q, Maity T and Sawadogo M: Ubiquitous expression of the 43- and 44-kDa forms of transcription factor USF in mammalian cells. Nucleic Acids Res 22: 427-433, 1994.

29. Aperlo C, Boulukos KE and Pognonec P: The basic region/helixloop-helix/leucine repeat transcription factor USF interferes with Ras transformation. Eur J Biochem 241: 249-253, 1996.

30. Qyang Y, Luo X, Lu T, Ismail PM, Krylov D, Vinson C and Sawadogo M: Cell-type-dependent activity of the ubiquitous transcription factor USF in cellular proliferation and transcriptional activation. Mol Cell Biol 19: 1508-1517, 1999.

31. Kutz SM, Higgins CE, Samarakoon R, Higgins SP, Allen RR, Qi L and Higgins PJ: TGF-beta 1-induced PAI-1 expression is E box/USF-dependent and requires EGFR signaling. Exp Cell Res 312: 1093-1105, 2006

32. Liu F and Green MR: Promoter targeting by adenovirus E1a through interaction with different cellular DNA-binding domains. Nature 368: 520-525, 1994.

33. Chang LS, Shi Y and Shenk T: Adeno-associated virus P5 promoter contains an adenovirus E1A-inducible element and a binding site for the major late transcription factor. J Virol 63: 3479-3488, 1989.

34. Galibert MD, Carreira S and Goding CR: The Usf-1 transcription factor is a novel target for the stress-responsive p38 kinase and mediates UV-induced Tyrosinase expression. EMBO J 20: 5022-5031, 2001.

35. Xiao Q, Kenessey A and Ojamaa K: Role of USF1 phosphorylation on cardiac alpha-myosin heavy chain promoter activity. Am J Physiol Heart Circ Physiol 283: H213-H219, 2002.

36. Cheung E, Mayr P, Coda-Zabetta F, Woodman PG and Boam DS: DNA-binding activity of the transcription factor upstream stimulatory factor 1 (USF-1) is regulated by cyclin-dependent phosphorylation. Biochem J 344 1: 145-152, 1999.

37. Nowak M, Helleboid-Chapman A, Jakel H, Martin G, DuranSandoval D, Staels B, Rubin EM, Pennacchio LA, Taskinen MR, Fruchart-Najib J and Fruchart JC: Insulin-mediated downregulation of apolipoprotein A5 gene expression through the phosphatidylinositol 3-kinase pathway: role of upstream stimulatory factor. Mol Cell Biol 25: 1537-1548, 2005.

38. Pietenpol JA, Stein RW, Moran E, Yaciuk P, Schlegel R, Lyons RM, Pittelkow MR, Munger K, Howley PM and Moses HL: TGF-beta 1 inhibition of c-myc transcription and growth in keratinocytes is abrogated by viral transforming proteins with pRB binding domains. Cell 61: 777-785, 1990.

39. Zimmermann H, Degenkolbe R, Bernard HU and O'Connor MJ: The human papillomavirus type 16 E6 oncoprotein can downregulate 553 activity by targeting the transcriptional coactivator CBP/p300. J Virol 73: 6209-6219, 1999.

40. Phelps WC, Yee CL, Münger K and Howley PM: The human papillomavirus type $16 \mathrm{E} 7$ gene encodes transactivation and transformation functions similar to those of adenovirus E1A. Cell 53: 539-547, 1988. 